\title{
Royal Air Force Emergency Rations
}

\author{
By D. G. V. Whittingham, R.A.F. Institute of Aviation Medicine
}

The range of present-day and future military aircraft makes emergency landings necessary on any part of the earth's surface. The possibility of the range of aircraft increasing is real, and with it goes the increased risk of precipitating men into adverse environments, especially in time of war. The policy of providing military aircraft with survival equipment of any kind is a controversial topic but, at the present moment, most military forces advocate the inclusion of survival equipment in all but the most unusual circumstances.

The types of ration to be considered here are those carried in aircraft. The emergency rations carried in marine craft or used during mountain rescue do not present the same problems, the most important problem with aircraft being the limitations of size and weight of the ration imposed by the nature of the small, complete survival pack. Almost all R.A.F. survival packs in the future will be stowed in the ejector seat, a device used for escape from single- or multi-seater aircraft. In an emergency the man and his seat are ejected clear of the fuselage as the first stage of a parachute descent. He is then separated from his seat and the survival pack remains attached to his buttocks.

Because of the limitations of work space in the cockpit, survival equipment must be of restricted size, and since the pack may have to be lifted from the cockpit by hand in escapes other than by seat ejection, for example crash landings, the equipment must not be heavy. Food is not the item of first importance in a survival pack. Protection from the environment is almost invariably the survivor's chief need, and if adequately protected his next need is rapid location. At sea as in the desert, his next requirement is water, and the ranking order of essentials usually has food in the fourth place.

The Royal Air Force requires, in practice, rations for two main situations. The first situation arises in sea survival where the principal task is to provide the man with an adequate supply of drinking water and a ration which will spare his body water to the utmost. The second situation arises during land-mass survival, desert and regions of very cold weather being excluded, where the need is not for water, which can be found, but for a ration which will support a high level of external work.

The dinghy survivor has need of fewer calories than his counterpart who is escaping and evading across a large land mass. The calorie density of the ration for the dinghy pack is not as vital as its antiketogenic and body-protein sparing powers, so carbohydrate would best predominate as a constituent. To the land-mass survivor, however, whose ability, time and opportunity to live off the land are often overstressed, the calorie density of his pack, its acceptability and satiety value are of great importance. The aircraft emergency ration may thus be called upon to 
serve two situations, the needs of which are fundamentally different. The greater the range of aircraft the more difficult it will be to predict which ration should be carried, at the best of times not an easy prediction during military flying.

From 1940 to 1945 the problem of which foodstuff to include in the pack was decided by its very small size, and two rations were introduced. One was a peanuts, oatmeal and molasses biscuit, providing units of $95^{\circ}$ Cal. weighing $8.5 \mathrm{oz}$. with a protein: fat: carbohydrate ratio of $x: 2 \cdot 5: 8$ by weight, and the other was of dried milk tablets, glucose (and benzedrine) providing units of $568 \mathrm{Cal}$. weighing 7.5 oz. with a ratio of $\mathrm{I}: 0.6: 8$. The peanuts, oatmeal and molasses biscuit was designed to be not highly acceptable in an attempt to help the survivor ration his meagre supply. Both of these rations have now been replaced by one composed entirely of glucose as hard candy, providing units of 592 Cal. and weighing $6.4 \mathrm{oz}$. This last ration, entirely of sugar, is used in the older generation of aircraft to-day.

The newer generations of aircraft with their ejector seats are capable of carrying a larger emergency pack than the old and, since a greater weight of food can be carried because of advances in the design of survival-radios, dinghies and other ancillary equipment, it is interesting to examine the suggestions as to which foodstuffs should be given for survival in different environments.

Roth (1948) was among the early advocates of a pure carbohydrate ration as a universal item. After a most elaborate series of experiments, and no doubt encouraged by the work of Gamble (1944, 1946-7), Roth launched American military opinion about survival rations along a path of enthusiasm for carbohydrate, from which it has never really deviated. In essence this approach maintains that if there is limitation in allowance for weight and space aboard aircraft for both food and water, the advantages of a survival ration must be appraised in terms of its cost to water balance. This view takes small cognizance of the possibility of the man landing on a terrain where water can be found, and gives greater importance to the fate of the dinghy survivor than of the man on land. Gamble (1944) considered the benefits of a carbohydrate ration of $100 \mathrm{~g}$ a day for fasting men who were not deprived of water. Hervey \& McCance $\left(\mathrm{I}_{95} \mathrm{I}-2\right)$ considered the saving in water which can be achieved when carbohydrate is eaten in circumstances of water lack. There remains the survivor who may have available I $500 \mathrm{Cal}$. a day or more for 4-5 days, who is not deprived of water. If the case is clear for sea survivors who may have to have a low caloric intake it does not necessarily follow that pure carbohydrate is ideal for all circumstances of survival.

Wickett \& Bliss (1952) when examining Royal Canadian Air Force survival rations, remarked on the body-protein sparing and anti-ketogenic effect of carbohydrate although they pointed out that rations containing fat had a high satiety value. For reasons similar to those advanced by Roth (1948) and later by Henschel, Quinn, Kleeman \& Bass (1953), a pure carbohydrate diet was recommended for survivors in all parts of the world.

Most assessments of survival rations describe the degree of change in electrolyte or nitrogen balance between carbohydrate and composite rations, but most workers are extremely reluctant to correlate such changes with a survivor's welfare in 
terms of exercise tolerance or psychological performance. It is not surprising that it should be so, for the measurement of human performance in any of its various forms can be a tantalizing and often unfruitful matter. The device used by recent investigators to avoid using the controversial performance indices has been to suggest that nitrogen and electrolyte imbalance will ultimately prove detrimental, and the longer the imbalance is postponed, the better. As a result a large number of survivors in the future will be expected to face the rigours of any environment, not only of the sea, on bars of jelly candy.

One of the most important factors in helping flying personnel to survive when reaching ground level after emergency escape from aircraft, is their training for such an event. Exercises simulating survival experiences are continually taking place in the R.A.F., and it has been possible during such training periods to examine some of the food preferences of men in the course of their rather arduous marches. A prominent feature of survival exercises is the great comfort and benefit to morale and fortitude a man may gain from acceptable hot food. This experience falls into line with that of men of the great classical explorations, who in the main preferred familiar foodstuffs of whose fortifying value they had personal experience. From six major field exercises in the R.A.F. in which a variety of rations has been tried by 200 men, a mixed ration containing $477 \mathrm{I}$ Cal. with a protein: fat: carbohydrate ratio of $\mathrm{I}: 2.8: 7.7$ has been found to give a high assessment for acceptability. These rations can be augmented to provide 6805 Cal. with a ratio of $I: 2.5: 5 \cdot 1$. The additional components are packed separately so that the container and contents of the $477 \mathrm{I} \mathrm{Cal}$. portion are left as a universal ration.

Acceptability of the food is of great importance to well-being and survival, and it would seem ill-advised to discard such an important factor together with a ration of high caloric density.

Attempts to show differences between groups of men on high-fat, mixed, and principally carbohydrate, rations, are not difficult in terms of metabolic chemistry. Unfortunately the significance of the chemical changes in so far as they affect survival performance is not so easy to demonstrate.

A recent pilot experiment has compared the influence of a high-fat ration and an antiketogenic ration on physical performance by the method advocated by Johnson, Brouha \& Darling (1942), and on psychological performance as measured by a battery of established tests chosen to cover as many fields of mental activity affecting a survivor during emergency as the testing time would allow. If there were any gross effect due to the high-fat diet that would have been dangerous to an actual survivor, it was assumed these tests could be reasonably expected to show it. The tests were chosen because they had to be used again and again on the same subject and because information concerning them was well known.

The psychological tests of performance were: (I) Memory-adding and subtracting (Kraepelin), (2) Memory-digit span (Binet), (3) Association-fluency, (4) Association-reaction time (Galton), (5) Relationships-completing series, 
(6) Reversible perspective frequency-(May Smith and McDougall), (7) Psychomotor-dotting machine (McDougall), (8) Perception of time estimation, (9) Level of aspiration, (Io) Unpaced reaction time (Leonnard's apparatus).

For two separate periods of $\mathrm{x} 20 \mathrm{~h}$ in an environment kept constant at $24^{\circ}$ and $25 \%$ relative humidity, each of two subjects consumed the high-fat and the control diet which by calculation contained protein, fat and carbohydrate in the ratio of $1: 4.5: 1 \cdot 4$ and $I: 0.9: 5.7$, respectively. Both diets provided about $1500 \mathrm{Cal} . /$ $\mathrm{man} /$ day. The water intake was maintained at $1300 \mathrm{ml}$. daily which, with the water content of the food and the water of oxidation, gave an average total per day of $185 \mathrm{I} \mathrm{ml}$. for the high-fat diet and $196 \mathrm{I} \mathrm{ml}$. for the control. Marching for $90 \mathrm{~min}$. at 3.5 m.p.h. up an incline of $8.6 \%$ was done daily in addition to an exercise tolerance run to exhaustion in the morning and afternoon of every day. The psychological battery of tests was divided into an hour's testing each morning and afternoon.

When on the control diets the subjects produced the minimum amount of ketone bodies in the urine. On the high-fat diet the amount of total acetone bodies in the urine rose progressively to a level on the $4^{\text {th }}$ day of $\mathrm{I} \cdot 4 \mathrm{~g}$ in one subject and of $0.9 \mathrm{~g}$ in the other. Both subjects showed an unexpected decrease in urinary excretion of ketones on the $5^{\text {th }}$ day.

Excretion of urinary nitrogen was not the same in the two subjects. In the one excreting the larger amount of ketones, nitrogen was excreted in greater quantity during the period on the high-fat diet than on the control diet. In the subject excreting the smaller quantity of ketones, there was no difference in the amount of urinary nitrogen between the periods on the control and high-fat diets.

The $\mathrm{CO}_{2}$-combining power of the blood followed a typical pattern related to the extent of the ketonaemia. The weight loss of the subjects on the high-fat diet was greater than on the control diet $(0.01>P>0.001)$. The physical tolerance indices of both subjects showed a significant slight depression during the periods of eating the high-fat diet. The physical tolerance indices were not significantly changed when the control diets were eaten.

The psychological testing showed no changes other than improvements due to learning and occasional simultaneous fluctuations of an unexpected nature in both subjects.

Here, then, is the familiar story of the situation which escapes judgment in the last analysis because the system of measurement may be imperfect. The present is not the occasion to discuss the frailties of exercise tolerance indices or the probity of psychological testing. What emerges from this pilot experiment is another confirmation of the belief that human metabolism can tolerate wider ranges of diet than would seem theoretically desirable. To expect men to eat a diet containing the quantity of fat or protein of the high-fat ration in this experiment would be absurd but, since there is apparently no gross detriment to a survivor's capabilities with even the low energy value of $1500 \mathrm{Cal}$. a day and a protein: fat: carbohydrate ratio of $1: 4 \cdot 5: 1 \cdot 4$, to exclude protein and fat from all survival rations and thereby markedly decrease the acceptability and calorie value of the rations, seems an unwarranted step. 
Dyme (1950) has shown that a daily ration of 133 I Cal. with a protein: fat: carbohydrate ratio of $\mathrm{I}: \mathrm{I} \cdot 3: 5$ requires an intake of $1000 \mathrm{ml}$. water to prevent dehydration. The R.A.F. emergency ration, $\mathrm{Mk}$. $\mathrm{V}$, which has a ratio of $\mathrm{I}: 2.5: 5.1$ and provides $1500 \mathrm{Cal}$. daily for 4 or 5 days, on extensive trials has been estimated to require about I $500 \mathrm{ml}$. The final step must be to assess the difference between a pure carbohydrate diet and the universal part of the Mk. V ration, with a ratio of $1: 2.8: 7 \cdot 7$, and providing $477 \mathrm{r} \mathrm{Cal}$,, in circumstances of a fluid water intake of the order of $560 \mathrm{ml}$. per head daily. The development of new processes for the desalination of sea water will affect the issue. At the moment an R.A.F. survivor would seem better placed with a ration suited to sea and land survival, even if not ideally perfect for the sea, than with a ration primarily suited to sea survival alone.

\title{
REFERENCES
}

Dyme, H. C. (1950). Tech. Rep. U.S. Air Force, no. 6019.

Gamble, J. L. (1944). Proc. Amer. phil. Soc. 88, I5 r.

Gamble, J. L. (1946-7). Harvey Lect. 42, 247.

Henschel, A., Quinn, M., Kleeman, C. R. \& Bass, D. E. (1953). Rep. Quarterm. gen. environmental Protection Branch, no. 20 .

Hervey, G. R. \& McCance, R. A. (1951-2). Proc. roy. Soc. B, 139, 527.

Johnson, R. E., Brouha, L. \& Darling, R. C. (1942). Rev. canad. Biol. I, 49 I.

Roth, J. L. D. (1948). Tech. Rep. U.S. Air Force, no. 5740.

Wickett, J. C. \& Bliss, J. Q. (1952). Rep. Canad. Def. Res. med. Lab., I.A.M. no. 52/4.

\section{Planning Food Supplies for Tropical Expeditions}

\author{
By B. S. Platt and R. H. Fox, Human Nutrition Research Unit, Medical Research \\ Council Laboratories, Holly Hill, London, N.W.3
}

\section{Special nutritional requirements in the tropics}

'A tropical climate is an aggressive climate and must be met aggressively' (Macpherson, 1949). To be able to do this effectively the influence of a hot climate on man must first be understood and then, armed with the knowledge, it is possible to plan ahead to meet the special requirements of life in the tropics. In the present paper the manner in which a tropical climate affects man's dietary needs and habits, and the general principles guiding the planning of food supplies, are discussed. The precise requirements of food and equipment for any one expedition must of course depend on the number of individuals, the amount of transport, the availability of local supplies, and the location and duration of the expedition. Ideal requirements may have to be modified to conform to a 'cost ceiling'.

Men living in hot climates are under stress; the degree of stress depends on the heat load of the environment and on the state of the individual exposed to it. The climatic factors that contribute to the heat load of the environment are: air temperature, air humidity, radiant heat flux, and air movement. The effective temperature scale (Houghten \& Yagloglou, I923), modified to include the influence of radiant 